\title{
A Case of Disease Improvement after Treatment with Everolimus plus Exemestane in a Patient with Hormone Receptor-Positive Metastatic Breast Cancer with Bone Metastases
}

\author{
J. Thaddeus Beck Ryan Mantooth \\ Highlands Oncology Group, Fayetteville, Ark., USA
}

Key Words

Everolimus · Hormone receptor · Advanced breast cancer

\begin{abstract}
Breast cancer is one of the most frequently diagnosed cancers and a leading cause of death in women worldwide. Despite significant advances in the treatment of hormone receptorpositive breast cancer, tumor metastasis occurs frequently and is associated with poor longterm prognosis. The mammalian target of rapamycin (mTOR) pathway plays a central role in cancer cell growth, proliferation, and resistance to endocrine therapies. Therefore, mTOR inhibitors such as everolimus in combination with nonsteroidal aromatase inhibitors might reverse endocrine resistance and improve clinical outcomes in patients. Here, we report on a case of infiltrating lobular carcinoma of the breast with metastases to the bone. Histopathologic analysis showed that the patient was estrogen and progesterone receptor positive and human epidermal growth factor- 2 negative. This case represents the clinical spectrum of complications caused by metastasis: the patient experienced a considerable amount of skeletal-related complications, had previously received chemotherapy, and experienced disease progression while taking nonsteroidal aromatase inhibitors. After treatment with oral everolimus $10 \mathrm{mg}$ daily plus oral exemestane $25 \mathrm{mg}$ daily, the patient's disease was ameliorated. Combination therapy was well tolerated, with minimal adverse effects that were manageable with concomitant medications. Although further analyses in larger populations are necessary, the addition of everolimus to exemestane might provide an effective new treatment option for patients with bone metastasis.

(C) 2015 S. Karger AG, Basel
\end{abstract}

KARGER 125/s $\begin{aligned} & \text { J. Thaddeus Beck } \\ & \text { Highlands Oncology Group } \\ & 3232 \text { N. North Hills Boulevard } \\ & \text { Fayetteville, AR 72703 (USA) } \\ & \text { E-Mail TBeck@hogonc.com }\end{aligned}$


Beck and Mantooth: A Case of Disease Improvement after Treatment with Everolimus plus Exemestane in a Patient with Hormone Receptor-Positive Metastatic Breast Cancer with Bone Metastases

\section{Introduction}

Breast cancer is one of the most frequently diagnosed cancers and a leading cause of death in women [1]. The standard of care for postmenopausal women with hormone receptor (HR)-positive advanced breast cancer is treatment with aromatase inhibitors [2]. Despite success with these agents, a major clinical problem in this patient population is endocrine therapy resistance (primary or acquired). Investigation into the mechanisms responsible for resistance to endocrine therapy has shown that the phosphatidylinositol 3-kinase (PI3K)/Akt/mammalian target of rapamycin (mTOR) pathway plays an important role [3, 4].

Constitutive activation of the PI3K/Akt/mTOR pathway in long-term estrogen-deprived cell culture models of breast cancer - conditions that mimic treatment with endocrine therapy - suggests that this signaling pathway is involved in endocrine resistance [5, 6]. Therefore, inhibition of mTOR represents a promising therapeutic target in HR-positive breast cancer. Everolimus, an oral mTOR inhibitor, has shown promise in patients with estrogen receptor (ER)-positive breast cancer [7]; more recently, everolimus in combination with exemestane improved progression-free survival (PFS) in postmenopausal women with ERpositive, human epidermal growth factor 2 (HER2)-negative, refractory advanced breast cancer that recurred or progressed after previous therapy with the nonsteroidal aromatase inhibitor letrozole or anastrozole [8, 9]. Herein, we report a case of primary breast cancer metastasis to distant sites with disease attenuation after treatment with everolimus plus exemestane.

\section{Case Presentation}

In October 2007, a 54-year-old woman received a diagnosis of bilateral infiltrating lobular carcinoma with concurrent bone metastases. The patient began a chemotherapy regimen of fluorouracil, doxorubicin, and cyclophosphamide and continued therapy for 4 months. In March 2008, she underwent a bilateral mastectomy, and histopathology revealed an ER- and PR-positive, HER2-negative tumor. After surgery, she received intravenous paclitaxel 175 $\mathrm{mg} / \mathrm{m}^{2}$ for four doses, followed by oral tamoxifen $20 \mathrm{mg}$ daily. In May 2008, she began radiation therapy for 5 weeks and remained in clinical remission. In August 2009, she underwent oophorectomy, stopped tamoxifen, and began treatment with oral anastrozole $1 \mathrm{mg}$ daily. In September 2011, new lytic bone disease developed in her thoracic spine at T12, but the disease was asymptomatic. This was associated with rising CA 27-29 levels. Positron emission tomography/computed tomography (PET/CT) with [ $\left.{ }^{18} \mathrm{~F}\right]$-fluorodeoxyglucose identified hypermetabolic lytic vertebral lesions that were confirmed by magnetic resonance imaging (MRI).

In October 2011, the patient began oral everolimus $10 \mathrm{mg}$ daily plus oral exemestane 25 mg daily (the BOLERO-2 trial was closed, but the patient received everolimus as part of her treatment regimen). In addition, the patient began intravenous zoledronic acid $4 \mathrm{mg}$ every 28 days. After 10 weeks of therapy, PET/CT demonstrated diminished activity in all sites (fig. 1). In addition, CA 27-29 levels decreased toward normal. Stomatitis was the chief adverse effect. It appeared within 2 weeks of therapy initiation and was managed with a mixture of topical lidocaine, diphenhydramine, antacid suspension ('magic mouthwash'), and good oral hygiene. The stomatitis, thought to be attributed to everolimus, was self-limiting and did not require interruption of treatment. Solitary focal lesions appeared intermittently and gradually diminished in size and intensity, and within 3 months of therapy the stomatitis resolved. 
Beck and Mantooth: A Case of Disease Improvement after Treatment with Everolimus plus Exemestane in a Patient with Hormone Receptor-Positive Metastatic Breast Cancer with Bone Metastases

In January 2012, the patient experienced low-grade fever and evening sweats. Zoledronic acid was held, but the fever did not resolve. A fever evaluation with chest X-ray and urine analysis, however, was unrevealing.

In March 2012, restaging using PET revealed continued improvement in bone. The patient then had focal jaw pain without visible stomatitis, but this was shown to be due to a dental abscess. In April 2012, her dental abscess was drained, she received a course of antibiotics, and the fever originally experienced in January resolved. At that time, she was taking acetaminophen, magic mouthwash (described earlier) for pain, and meloxicam for osteoarthritis. In December 2012, her CA 27-29 blood levels rose, and new hypermetabolic lesions were seen on PET and confirmed on MRI. Everolimus and exemestane were stopped in January 2013.

\section{Discussion}

Treatment options are limited for postmenopausal women with HR-positive advanced breast cancer who experience disease recurrence or progression. In the BOLERO-2 trial at 18 months' follow-up, everolimus plus exemestane resulted in a 4.6-month prolongation of the median PFS, from 3.2 months in the placebo plus exemestane group to 7.8 months in the everolimus plus exemestane group [hazard ratio (HR), 0.45; 95\% confidence interval (CI), $0.38-0.54 ; \mathrm{p}<0.0001$ ] [9]. The objective response rate (ORR) and clinical benefit rate (CBR) were significantly higher in the everolimus plus exemestane group than in the placebo plus exemestane group [9]. The ORR was $12.6 \%$ for everolimus plus exemestane and $1.7 \%$ for placebo plus exemestane ( $\mathrm{p}<0.0001)$; the CBR was $51.3 \%$ for everolimus plus exemestane and $26.4 \%$ for placebo plus exemestane $(\mathrm{p}<0.0001)$ [9].

This case report presents a woman in her 50s with a diagnosis of advanced breast cancer with bone metastases in distant sites. Within 10 weeks of treatment with everolimus plus exemestane, she experienced disease improvement (as determined radiographically). Previous exploratory analyses of the BOLERO-2 study evaluated the effect of everolimus plus exemestane on bone disease progression. One exploratory analysis determined that everolimus plus exemestane, compared with exemestane alone, reduced the levels of markers indicative of bone turnover [10]. Additionally, the everolimus combination, compared with exemestane alone, reduced the incidence of progressive disease in bone in both the overall patient population and the subset of patients with baseline bone metastases [10]. Another subanalysis of the BOLERO-2 study found that, for patients with bone-only metastases, everolimus plus exemestane, compared with exemestane alone, improved PFS (12.88 vs. 5.29 months; HR, 0.33; 95\% CI, 0.21-0.53; $\mathrm{p}<0.05$ ) [11].

In conclusion, this case report supports the use of everolimus plus exemestane in postmenopausal women with HR-positive advanced breast cancer with bone metastases whose disease progressed on a nonsteroidal aromatase inhibitor. To confirm this finding, future analyses in larger populations of patients with HR-positive breast cancer and bone metastases are necessary. 


\section{Case Reports in Oncology}

\begin{tabular}{l|l}
\hline \multicolumn{2}{l|}{ Case Rep Oncol 2015;8:101-105 } \\
\hline DOI: $10.1159 / 000375119$ & $\begin{array}{l}\text { C 2015 S. Karger AG, Basel } \\
\text { www.karger.com/cro }\end{array}$ \\
\hline
\end{tabular}

Beck and Mantooth: A Case of Disease Improvement after Treatment with Everolimus plus Exemestane in a Patient with Hormone Receptor-Positive Metastatic Breast Cancer with Bone Metastases

\section{Acknowledgements}

The authors thank Matthew Grzywacz, PhD, of ApotheCom (Yardley, Pa., USA) for editorial and technical assistance in the development of the manuscript. Novartis Pharmaceuticals Corporation provided funding for the development of the manuscript.

\section{Disclosure Statement}

Dr. Beck has received research support from Roche, Genentech, Eli Lilly, and Novartis. Dr. Mantooth has nothing to disclose.

\section{References}

1 Jemal A, Bray F, Center MM, Ferlay J, Ward E, Forman D: Global cancer statistics. CA Cancer J Clin 2011;61:69-90.

2 National Comprehensive Cancer Network: NCCN Clinical Practice Guidelines in Oncology. Breast Cancer. Version 1.2014. Fort Washington, National Comprehensive Cancer Network, 2014.

-3 Gnant M: The role of mammalian target of rapamycin (mTOR) inhibition in the treatment of advanced breast cancer. Curr Oncol Rep 2013;15:14-23.

4 Yamnik RL, Holz MK: mTOR/S6K1 and MAPK/RSK signaling pathways coordinately regulate estrogen receptor alpha serine 167 phosphorylation. FEBS Lett 2010;584:124-128.

5 Miller TW, Hennessy BT, Gonzalez-Angulo AM, et al: Hyperactivation of phosphatidylinositol-3 kinase promotes escape from hormone dependence in estrogen receptor-positive human breast cancer. J Clin Invest 2010;120:2406-2413.

-6 Yue W, Fan P, Wang J, Li Y, Santen RJ: Mechanisms of acquired resistance to endocrine therapy in hormonedependent breast cancer cells. J Steroid Biochem Mol Biol 2007;106:102-110.

-7 Bachelot T, Bourgier C, Cropet C, et al: Randomized phase II trial of everolimus in combination with tamoxifen in patients with hormone receptor-positive, human epidermal growth factor receptor 2-negative metastatic breast cancer with prior exposure to aromatase inhibitors: a GINECO study. J Clin Oncol 2012;30:2718-2724.

-8 Baselga J, Campone M, Piccart M, et al: Everolimus in postmenopausal hormone receptor-positive advanced breast cancer. N Engl J Med 2012;366:520-529.

-9 Yardley DA, Noguchi S, Pritchard KI, et al: Everolimus plus exemestane in postmenopausal patients with HR+ breast cancer: BOLERO-2 final progression-free survival analysis. Adv Ther 2013;30:870-884.

10 Gnant M, Baselga J, Rugo HS, et al: Effect of everolimus on bone marker levels and progressive disease in bone in BOLERO-2. J Natl Cancer Inst 2013;105:654-663.

11 Campone M, Bachelot T, Gnant M, et al: Effect of visceral metastases on the efficacy and safety of everolimus in postmenopausal women with advanced breast cancer: subgroup analysis from the BOLERO-2 study. Eur J Cancer 2013;49:2621-2632. 


\section{Case Reports in Oncology}

\begin{tabular}{l|l}
\hline \multicolumn{2}{l}{ Case Rep Oncol 2015;8:101-105 } \\
\hline DOI: $10.1159 / 000375119$ & $\begin{array}{l}\text { C 2015 S. Karger AG, Basel } \\
\text { www.karger.com/cro }\end{array}$ \\
\hline
\end{tabular}

www.karger.com/cro

Beck and Mantooth: A Case of Disease Improvement after Treatment with Everolimus plus Exemestane in a Patient with Hormone Receptor-Positive Metastatic Breast Cancer with Bone Metastases
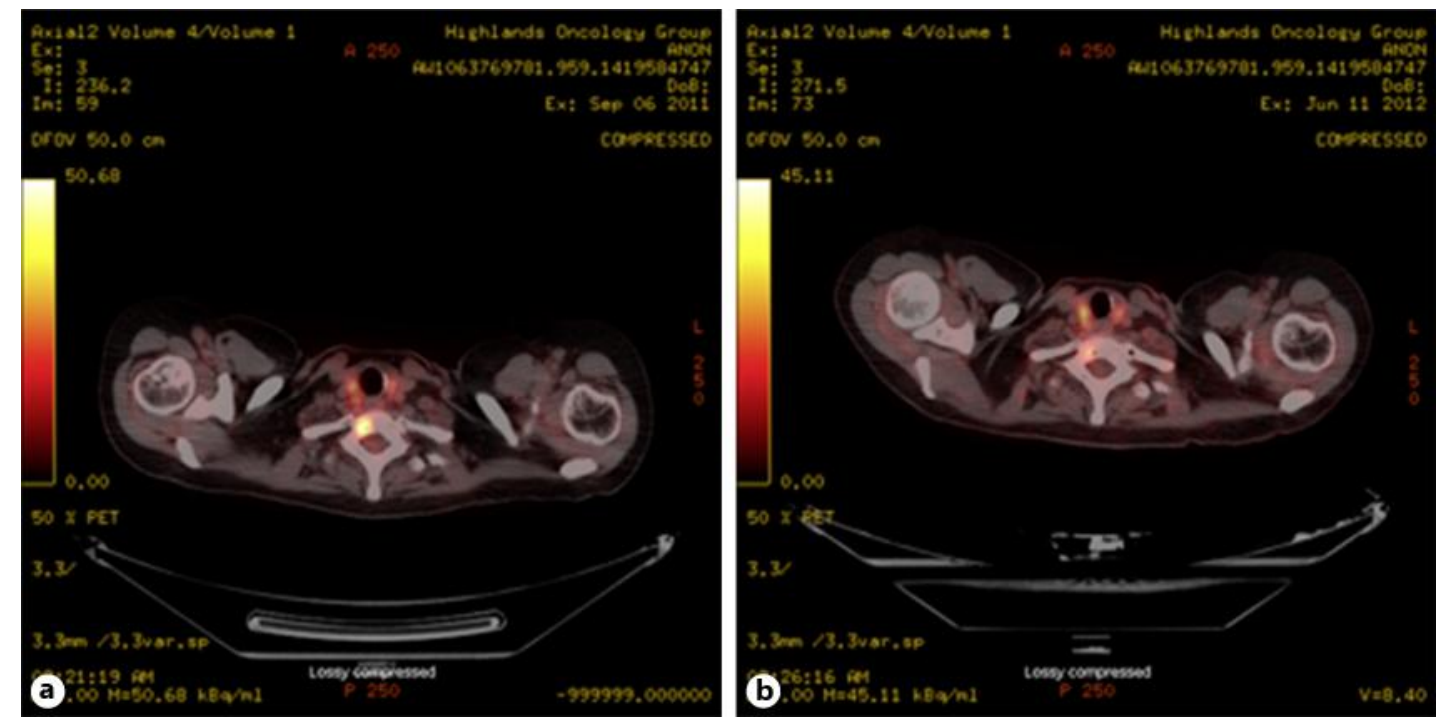

Fig. 1. PET/CT scan with [18F]-fluorodeoxyglucose of hypermetabolic lytic vertebral lesions before (a) and after (b) 10 weeks of everolimus plus exemestane therapy. 